\title{
ESTADO DE EXCEÇÃO E A GOVERNAMENTALIDADE DA VIDA: A GUERRA COMO PARADIGMA POLIITICO'
}

\author{
State of exception and the governmentality of life: war as \\ political paradigm
}

Estado de excepción y la gubernamentalidad de la vida: la guerra como paradigma político

Evandro Pontel ${ }^{2}$

Pontifícia Universidade Católica do Rio Grande do Sul, Porto Alegre, RS, Brasil.

\section{Resumo}

A presente reflexão visa investigar a concepção de estado de exceção enquanto dispositivo de governamentalidade que inclui a vida por meio do direito, pelo uso da exceção firmada como norma, o que coloca a vida e o Direito em uma íntima relacionalidade. Esse dispositivo instituído pela exceção jurídica firmada pela decisão soberana estabelece mecanismos e estratégias de poder que inserem e produzem novas modalidades de controle sobre a vida, paradigma de decisionismo soberano,

\footnotetext{
O presente artigo resulta de uma pesquisa mais ampla, realizada durante o Doutorado em Filosofia, intitulada: "Estado de exceção permanente: a condição humana e a política no ocidente entre a vida (nua) e o (bio)poder no pensamento de Giorgio Agamben", com financiamento do CNPq.

2 Doutor e pós-doutorando em Filosofia, Escola de Humanidades, Programa de Pós-Graduação em Filosofia, Pontifícia Universidade Católica do Rio Grande do Sul (PUCRS). http://orcid. org/0000-0002-9659-4231. E-mail: epontel@hotmail.com
} 
que faz coincidir excepcionalismo e governamentalidade. Esse paradigma de exercício do poder assente no decisionismo soberano faz com que o Direito e as instituições democráticas se tornem instâncias de subtração de direitos. Esse dado basilar gera uma situação paradoxal diante da modernidade, sua concepção do político e de soberania enquanto garantia de direitos e de autonomia dos indivíduos. Essa configuração coloca em xeque o significado que o Direito e a própria vida passam a ter no tempo presente.

Palavras-chave: Estado de exceção. Exceção. Poder. Soberania. Biopoder.

\begin{abstract}
This reflection aims to investigate the conception of State of exception while device that includes the life through the law, by the use of this exception established as standard, which places the Life and the law in an intimate relationality. This device set up by legal exception established by sovereign decision establishes mechanisms and strategies of power that inserts and produces new forms of control over life - which coincides with exceptionalism and governmentality. This paradigm of exercise of power based on the sovereign decision-making powers causes the right and democratic institutions become instances of subtraction. This Foundation generates a paradoxical situation in the face of modernity, your conception of sovereignty and political rights guarantee and while autonomy of individuals. This setting put in check the meaning that the law and life itself are at the present time.
\end{abstract}

Keywords: State of exception. Exception. Power. Sovereignty. BioPower.

\title{
Resumen
}

Esta reflexión tiene como objetivo investigar la concepción del estado de excepción como el dispositivo de gubernamentalidad que incluye la vida a través de la ley, el uso de la excepción establecida como estándar, que pone la vida y la ley en una íntima relacionalidad. Este dispositivo establecido por la excepción jurídica se firma por medio de la decisión soberana que fija mecanismos y estrategias de poder que inserta y produce nuevas formas de control sobre la vida, - paradigma del poder de decisión soberano - que hace coincidir gubernamentalidad y excepcionalidad. Este paradigma del ejercicio del poder tiene su base en el decisionismo soberano que hace que el derecho y las instituciones democráticas se convierten en instancias de sustracción. Este dado fundamental genera una situación paradójica frente a la modernidad, su concepción de lo político, de la soberanía y los derechos mientras que deberían ga- 
rantizar la autonomía de los individuos. Este escenario puso en jaque el significado que la ley y la vida misma en la actualidad.

Palabras clave: Estado de excepción. Excepción. Poder. Soberanía. Biopoder.

"O estado de exceção tende cada vez mais a se apresentar como o paradigma dominante na política contemporânea"s

Vivemos na contemporaneidade um cenário de plena expansividade de naturalização da violência e de produção do medo ${ }^{4}$. Essa constatação compreende e sinaliza para um movimento de crescente espiral ascendente, seja em âmbito social, seja por parte dos "Estados" democráticos de direito constituídos. Nessa esteira, os governos agem por meio de dispositivos jurídicos e securitários, a partir dos quais atuam sob um discurso fundado em "razões de segurança", e de "soberania nacional". A partir desse paradigma de governamentalidade adotam uma série de procedimentos de exceção que têm se configurado como técnica de governabilidade, em que frente determinada "[...] ameaça imediata e real que deve ser eliminada ao se suspender por um tempo limitado as garantias da lei; as "razões de segurança" de que falamos hoje constituem, ao contrário, uma técnica de governo normal e permanente"5.

A teorização desse instituto jurídico parte de uma abordagem genealógica e paradigmática em vista de situá-lo no limiar da contemporaneidade, analisando as consequências decorrentes do estado de exceção em âmbito jurídico-político e o significado da ação política nos tempos atuais.

\footnotetext{
3 AGAMBEN, Giorgio. Estado de exceção. Tradução: Iraci D. Poleti. 2. ed. São Paulo: Boitempo, 2004, p. 13.

4 Ver: BARBER, Benjamin R. O império do medo: guerra, terrorismo e democracia. Tradução Renato Bittencourt. Rio de Janeiro: Record, 2005; DOUZINAS, Costas. O fim dos direitos humanos. Tradução: Luzia Araújo. São Leopoldo: Unisinos, 2009.

5 AGAMBEN, Giorgio. Uma cidadania reduzida a dados biométricos: como a obsessão securitária faz mudar a democracia. In: (orgs.). GLOECKNER, Ricardo Jacobsen; FRANÇA, Leandro Ayres; RIGON, Bruno Silveira. Biopolíticas: estudos sobre política, governamentalidade e violência. Tradução: Daniel Arruda Nascimento, Curitiba: iEA Academia, 2015, p. 126.
} 
Na modernidade o estado de exceção - "suspensão, paralisação da lei", que produz um vácuo, uma espécie de anomia, - "vazio jurídico", - que continua a operar de modo permanente sob formas multidimensionais e pluriformes, nas mais distintas realidades, em que o campo de concentração é o paradigma moderno do nomos. Nele, de acordo com Giorgio Agamben7 a "vida nua atinge sua máxima indeterminação", em que este dispositivo jurídico-político se torna regra, o paradigma que domina a governabilidade, culminando com a instauração de uma "guerra civil global"8.

A abordagem desse instituto jurídico-político em sentido de regra e técnica de governo se dá a partir de um diálogo profundo entre dois gigantes: Walter Benjamin e Carl Schmitt ${ }^{9}$. A partir da questão da soberania, o pensador italiano se debruça sobre o tema do "estado de exceção", partindo da análise prospectiva que havia uma lacuna na doutrina jurídica e no campo da filosofia política acerca desse tema - desenvolvendo uma genealogia desse instituto jurídico-político, o dispositivo que suspende a lei e captura a vida do "vivente". Os pensadores supramencionados são os pilares sobre os quais toda a discussão em torno ao tema do estado de exceção se desenvolve. Isto é, a genealogia acerca desse instituto jurídico-político reconstrói-o desde sua gênese até os tempos atuais, mas

\footnotetext{
6 O ponto de partida na obra Estado de exceção situa um prognóstico que mostra que na atualidade, ainda falta uma concisa "[...] teoria do estado de exceção no direito público, e tanto juristas quanto especialistas em direito público parecem considerar o problema muito mais como uma quaestio facti do que como um genuíno problema jurídico". AGAMBEN, Giorgio. Estado de exceção. Tradução: Iraci D. Poleti. 2. ed. São Paulo: Boitempo, 2004, p. 12 (grifo do autor).

7 Para um panorama geral da obra de Giorgio Agamben, consultar: DURANTEYE, Leland de la. Giorgio Agamben: a critical introduction. Stanford: Stanford University Press, 2009. CASTRO, Edgardo.Introdução a Giorgio Agamben: uma arqueologia da potência. Tradução: Beatriz de Almeida Magalhães. Belo Horizonte: Autêntica, 2012.

8 Cf. AGAMBEN, Giorgio. Stasis: la guerra come paradigma politico. Totino: Bollati Boringhieri, 2015.

9 Frente ao escopo da presente pesquisa, não nos deteremos em detalhar a posição de cada um dos pensadores em particular, pois seus contributos essenciais são recorrentes na teorização de Giorgio Agamben. Entretanto, uma leitura da posição de ambos e suas especificidades, pode ser conferida em: Estado de exceção e (in)decisão soberana: exceção jurídica e soberania. In: PONTEL, Evandro. Estado de exceção: estudo em Giorgio Agamben. Passo Fundo: Ifibe, 2014, p. 67-107.
} 
tendo como pano de fundo esses dois gigantes ${ }^{10}$, como bem expressa 0 pensador italiano em sua obra.

No decorrer da exposição, podemos perceber que o profundo diálogo será desenvolvido tendo como foco explicitar as tradições jurídicas que defendem abertamente a inserção do estado de exceção no âmbito jurídico, enquanto parte integrante do direto positivo, sob a alegação que a "necessidade" é fonte autônoma do direito, quanto, por outro lado, as posições diametralmente opostas, que consideram o estado de exceção exterior ao ordenamento. Isto é, nessa segunda posição, se exclui a possibilidade de regulamentação do estado de exceção determinado por lei, o que não pode ser normatizado. Portanto, trata-se de um fenômeno fundamentalmente político e extrajurídico.

De acordo com a análise agambeniana, somente a partir do confronto entre os modelos "jurídico-institucional" e o modelo "biopolítico", é que se torna possível desvendar "este oculto ponto de intersecção entre o modelo jurídico-institucional e o modelo biopolítico do biopoder"1". $\mathrm{O}$ ponto fundamental reside na radicalidade de interpretar os institutos fundamentais do direito e da política, propriamente no espaço onde foram intrincadas e enredadas estas categorias, e a relação entre a vida nua e a política em voga na atualidade, sob um viés biopolítico ${ }^{12}$. A partir desse

\footnotetext{
10 As obras de referência para todo o debate em torno ao qual se desenvolve a problematização na obra Estado de exceção são: BENJAMIN, Walter. Crítica da violência - crítica do poder. In: Documentos de cultura, documentos de barbárie. São Paulo: Cultrix, 1986; BENJAMIN, Walter. Origem do drama trágico alemão. Tradução e edição de João Barrento. Belo Horizonte: Autêntica, 2012]; [SCHMITT, Carl. Teologia política. Tradução: Elisete Antoniuk. Belo Horizonte: Del Rey, 2006]. Márcio Seligmann-Silva apresenta detalhadamente o emergir dos escritos de cada um dos autores e o panorama do pós-guerra no qual emergem. Ver: SELIGMANN-SILVA, Márcio. Walter Benjamin: o Estado de Exceção entre o político e o estético. Cadernos Benjaminianos. n. 1, 2009, p. 1-23.

1 AGAMBEN, Giorgio. Homo sacer: o poder soberano e a vida nua I. Tradução: Henrique Burigo. 2. ed. Belo Horizonte: UFMG, 2010, p. 14.

12 "Somente em um horizonte biopolítico, de fato, será possível decidir se as categorias sobre cujas oposições fundou-se a política moderna (direita/esquerda; privado/público; absolutismo/ democracia etc.), e que se foram progressivamente esfumando a ponto de entrarem hoje numa verdadeira e própria zona de indiscernibilidade, deverão ser definitivamente abandonadas ou poderão eventualmente reencontrar a significado que naquele próprio horizonte haviam
} 
embate conceitual buscaremos explicitar e compreender o dispositivo ${ }^{13}$ em que o direito se refere à vida, a captura, a inclui em si por meio da própria suspensão, "inclusão exclusiva-exclusão inclusiva", por meio da qual se poderá entender a política e este espaço anômico (vazio jurídico, isto é, a lei que se relaciona com a vida por meio da sua própria suspensão exceção jurídica, como paradigma dominante de governo nas sociedades atuais. Em vista de se explicitar essa zona oculta e incerta, o desafio é tornar claro de fato "[...] o que está em jogo na diferença - ou na suposta diferença entre o poder político e o jurídico e entre o direito e o vivente"14, um patamar de indistinção, o "estado de exceção" que emerge e tende a tornar-se regra, o paradigma de governo na contemporaneidade.

A configuração desse paradigma de governo da vida age em torno da vida e sobre a vida, pois é sobre ela que se dá a decisão soberana, em que por meio do direito se captura a vida do "vivente" e determina que vidas devem ser conservadas e quais vidas podem ser eliminadas, que são passíveis de descartabilidade, matáveis, mera "vida nua". Disso decorre o caráter biopolítico desse instituto jurídico-político. Isso indica para o desafio de situar o estado de exceção, "paradigma da política de segurança e controle sobre os cidadãos como forma de conceber a própria política”15, em seu caráter biopolítico que, finalmente tende a

perdido". AGAMBEN, Giorgio. Homo sacer: o poder soberano e a vida nua I. Tradução: Henrique Burigo. 2. ed. Belo Horizonte: UFMG, 2010, p. 12.

13 Por dispositivo se compreende "[...] qualquer coisa que tenha de algum modo a capacidade de capturar, orientar, determinar, interceptar, modelar, controlar e assegurar os gestos, as condutas, as opiniões e os discursos dos seres viventes". AGAMBEN, Giorgio. O que é o contemporâneo? e outros ensaios. Tradução: Vinícius Nicastro Honesko. Chapecó: Argos, 2009, p. 40. 14 AGAMBEN, Giorgio. Estado de exceção. Tradução: Iraci D. Poleti. 2. ed. São Paulo: Boitempo, 2004, p. 12.

15 Para Giorgio Agamben, “[...] o totalitarismo moderno pode ser definido, nesse sentido, como a instauração, por meio do estado de exceção, de uma guerra civil legal que permite a eliminação física não só dos adversários políticos, mas também de categorias inteiras de cidadãos que, por qualquer razão, pareçam não integráveis ao sistema político" [apresentando-se, por excelência, o estado de exceção, como um patamar de indistinção entre democracia e absolutismo] AGAMBEN, Giorgio. Estado de exceção. Tradução: Iraci D. Poleti. 2. ed. São Paulo: Boitempo, 2004, p. 13. 
se tornar "tanatopolítica"16. Isto é, o humano em condição de iminente exposição à morte, em que Guantánamo ilustra de modo ímpar a "vida nua" em sua "máxima indeterminação" - vida precária - vida sem direto a ter direitos garantidos"17.

É precisamente nesse viés que poder-se-ia ilustrativamente situar os mecanismos de controle via decretos com "força-de-lei", criados no pós 11 de setembro de 2001, pelo governo de G. W. Bush, nos Estados Unidos, dispositivos que preveem a implantação de medidas e procedimentos judiciais e extrajudiciais de restrição de direitos e liberdades dos cidadãos, com a justificativa de sustentar a "segurança" e a "ordem". Nesse ínterim, permite-se manter preso o estrangeiro (alien) suspeito de atividades que ponham em risco a segurança nacional podendo ser expulso do país sob a alegação de violação da lei sobre imigração. Logo, essa 'ordem' captura a vida do vivente, anulando radicalmente todo o estatuto jurídico e suas garantias, produzindo “[...] um ser juridicamente inominável e inclassificável”"18 em uma situação de vida exposta, pois “[...] quando o direito é

16 "O termo tanatopolítica tem como prefixo a derivação de Tânatos: o personagem da mitologia grega que personifica ou comunica a morte, aquele que conduz os seres humanos ao Hades, o mundo inferior dos mortos". NASCIMENTO, Daniel Arruda. Do fim da experiência ao fim do jurídico: percurso de Giorgio Agamben. São Paulo: LiberArs, 2012, p. 175.

17 Cf.: Capítulo 3. Detención indefinida In: BUTLER, Judith. Vida precaria: el poder del duelo y la violencia. Tradução: Fermín Rodríguez. Buenos Aires: Paidós, 2006, p. 79-132. Ainda, na obra Quadros de guerra: quando a vida é passível de luto? Judith Butler retoma a exposição da obra citada inicialmente, na qual afirma que a precariedade da vida é um dado básico, o qual se faz necessário ter presente para ler os tempos atuais, tempo de guerra, em que a violência assume formas múltiplas, sobretudo as legitimadas pelos aparatos estatais que propugnam guerras em nome da defesa da vida, mesmo que para isso seja preciso, paradoxalmente, eliminar vidas: "Que vidas são consideradas vidas que merecem ser salvas e que vidas não o são? [...] quais vidas são consideradas valiosas, quais vidas são enlutadas, e quais vidas consideradas não passíveis de luto". BUTLER, Judith. Quadros de guerra: quando a vida é passível de luto? 3. ed. Tradução: Sérgio Tadeu de Niemayer Lamarão e Arnaldo Marques da Cunha. Rio de Janeiro: Civilização Brasileira, 2017, p. 64.

18 AGAMBEN, Giorgio. Estado de exceção. Tradução: Iraci D. Poleti. 2. ed. São Paulo: Boitempo, 2004, p. 14. 
suspendido da ordem na forma de exceção, a vida humana fica a mercê da vontade soberana de quem governa"19. Logo:

O que ocorreu e ainda está ocorrendo sob nossos olhos é que o espaço "juridicarnente vazio" do estado de exceção (em que a lei vigora na figura - ou seja, etimologicamente, na ficção - da sua dissolução, e no qual podia portanto acontecer tudo aquilo que o soberano julgava de fato necessário) irrompeu de seus confins espaço-temporais e, esparramando-se para fora deles, tende agora por toda parte a coincidir com o ordenamento normal, no qual tudo se torna assim novamente possível. ${ }^{20}$

No entendimento do pensador italiano, vale destacar, foi Carl Schmitt quem estabeleceu a essencial contiguidade entre estado de exceção e soberania. Na obra Teologia política Carl Schmitt estabelece e delimita o conceito de soberania em estreita relação com o poder soberano, enraizado e estribado na decisão sobre o estado de exceção, explícito na afirmação: "Soberano é quem decide sobre o estado de exceção" ${ }^{\prime 2}$. Nesse interstício, salienta e esclarece que esta definição indica um conceito limítrofe e, portanto, não pode ser vinculado ao caso normal, tendo que ser entendido na perspectiva de um conceito geral da teoria do Estado, mas não qualquer ordem de necessidade, mas em um âmbito de uma definição jurídica de soberania sustentada em um motivo sistemático, lógico-jurídico.

No viés dessa configuração de um conceito limítrofe, podemos compreender a suma importância do soberano, que detém a prerrogativa e o poder de criar a ordem, garantir uma situação como um todo em sua

19 RUIZ, Castor Mari Martín Bartolomé. Introdução. In: RUIZ, Castor Mari Martín Bartolomé. (org.) Justiça e memória: direito à justiça, memória e reparação, a condição humana nos estados de exceção, 2012, p. 11.

20 AGAMBEN, Giorgio. Homo sacer: o poder soberano e a vida nua I. Tradução Henrique Burigo. 2. ed. Belo Horizonte: UFMG, 2010, p. 44. (grifo do autor).

${ }^{21}$ SCHMITT, Carl. Teologia política. Tradução Elisete Antoniuk. Belo Horizonte: Del Rey, 2006, p. 7. 
completude, pois tem o poder de decisão. Desse modo, o estado de exceção revela e evidencia a natureza essencial da autoridade estatal, a capacidade de decidir tanto sobre

[...] a ocorrência do estado de necessidade extremo, bem como sobre o que se deve fazer para saná-lo. O soberano se coloca fora da ordem jurídica normalmente vigente, porém a ela pertence, pois ele é competente para a decisão sobre se a Constituição pode ser suspensa in toto ${ }^{22}$

A condição peculiar conferida ao soberano por meio da sua soberania, aquele que age e toma a decisão, cuja figura que determina o estado de exceção também revela na própria exceção a sua essência, o seu ser, pois esse também permanece em uma relação paradoxal. Ao mesmo tempo em que pertence à lei, ao que está previsto nela, coloca-se fora da lei. Isso fica evidente na exposição schmittiana, perspectiva da qual o pensador italiano parte para sistematizar essa paradoxal relação. Na medida em que o soberano detém o poder legal de suspender a validade de uma norma, coloca-se legalmente fora da norma.

Nesse âmbito, Giorgio Agamben, relendo a obra schmittiana, considera e ilustra tal paradoxo, como se lê: "a lei está fora dela mesma, ou então: 'eu soberano, que estou fora da lei, declaro que não há um fora da lei'”23. Dito de outro modo: se é o "soberano quem decide sobre o estado de exceção"24, onde está incluído no direito a sua própria suspensão ${ }^{25}$, este

\footnotetext{
22 SCHMITT, Carl. Teologia política. Tradução: Elisete Antoniuk. Belo Horizonte: Del Rey, 2006, p. 8.

23 AGAMBEN, Giorgio. Homo sacer: o poder soberano e a vida nua I. Tradução Henrique Burigo. 2. ed. Belo Horizonte: UFMG, 2010, p. 23.

${ }_{24}$ SCHMITT, Carl. Teologia política. Tradução: Elisete Antoniuk. Belo Horizonte: Del Rey, 2006, p. 7.

25 A relação de exclusão é caracterizada como uma relação de bando, uma das primigênias estruturas político-jurídicas civilizatórias, em que a lei aplica-se desaplicando-se: [...] o relacionamento jurídico-político originário é o bando, não é apenas uma tese sobre a estrutura formal da soberania, mas tem caráter substancial, porque o que o bando mantém unidos são justamente a vida nua e o poder soberano. É preciso dispensar sem reservas todas as representações do
} 
inscreve-se no contexto jurídico, mesmo que a sua efetivação implique na 'suspensão de toda ordem jurídica', o que acaba por articular a exceção e a ordem jurídica, via decisão soberana, em que a força soberana define a vida humana. De acordo com Carl Schmitt, "Sendo o estado de exceção algo diferente da anarquia e do caos, subsiste, em sentido jurídico, uma ordem, mesmo que não uma ordem jurídica" ${ }^{26}$. Nessa senda, se ao soberano cabe instaurar o estado de exceção, destaca-se o caráter decisionista, e isto implica o fato da própria decisão, em usar tal dispositivo. ${ }^{27}$

Na obra Origem do drama trágico alemão, Walter Benjamin opera uma inversão na compreensão da soberania schmittiana e explicita a sua "Teoria da Soberania", a nova ordem política. Assim, "O conceito moderno de soberania tende para um poder executivo supremo assumido

ato político originário como um contrato ou uma convenção, que assinalaria de modo pontual e definido a passagem da natureza ao Estado. Existe aqui, ao invés, uma bem mais complexa zona de indiscernibilidade entre nómos e phýsis, na qual o liame estatal, tendo a forma do bando, é também desde sempre não estatalidade e pseudonatureza, e a natureza apresenta-se desde sempre como nómos e estado de exceção". AGAMBEN, Giorgio. Homo sacer: o poder soberano e a vida nua I. Tradução: Henrique Burigo. 2. ed. Belo Horizonte: UFMG, 2010, p. 44. (Grifo do autor). O pensador italiano remonta ao escrito Diante da Lei de Franz Kafka, com vistas à ilustar de modo exemplar da estrutura do bando soberano, pois nada impede ao camponês que ingresse, que entre pela porta da lei, pois nem sequer há recusa por parte do guardião, uma vez que a porta está desde sempre aberta, e a lei não prescreve nada. De acordo com o esquema da exceção soberana, a lei aplicasse-Ihe desaplicando-se, o mantém em seu bando abandonando-o fora de si. A porta aberta, que é destinada somente a ele, o inclui excluindo-o e exclui incluindo-o. Ver: KAFKA, Franz. Ante la ley. In: Obras completas. Tradução: Joan Bosch Estrada [et al.]. [Tomo IV], p. 1131-1133.

${ }_{26}$ SCHMITT, Carl. Teologia política. Tradução: Elisete Antoniuk. Belo Horizonte: Del Rey, 2006, p. 13.

${ }_{27}$ Gilberto Bercovici precisa a posição de Schmitt: "Soberano é quem decide sobre o estado de exceção". Com esta célebre frase, que inicia seu livro Teologia Política, Carl Schmitt destacou a soberania com uma função politicamente indispensável para afirmar uma ordem. O sentido concreto da controvérsia sobre soberania se dá sobre aquele que decide, em caso de conflito, em que consiste o interesse público e o do Estado, a segurança e a ordem públicas. A necessidade do soberano era por ele interpretada na inafastabilidade da exceção, na normalidade da exceção. A soberania é a "competência" imprevisível, estranha às normas de direito público, pois não se trata do término do direito, mas de sua própria origem. Para Schmitt, a soberania era a afirmação da ordem e, ao mesmo tempo, a sua negação. Deste modo, definir a soberania como decisão sobre o estado de exceção significa dizer que o ordenamento está à disposição de quem decide. O soberano, assim está ao mesmo tempo, dentro e fora da lei". BERCOVICI, Gilberto. Constituição e estado de exceção permanente: atualidade de Weimar. Rio de Janeiro: Azougue Editorial, 2004, p. 65-66. 
pelo príncipe, o Barroco desenvolve-se a partir da discussão do estado de exceção, considerando que a mais importante função do Príncipe é impedi-lo"28. Isto é, aquele que exerce o poder está predestinado de antemão a ser detentor de um poder ditatorial em situações de exceção provocadas por guerras, revoltas ou outras catástrofes. Nesse cenário, o que caracteriza o soberano é a indecisão, isto é, trata-se da incapacidade de decidir: "O Príncipe, cuja pessoa é depositária da decisão do estado de exceção demonstra-se logo na primeira oportunidade que é incapaz de tomar uma decisão"29.

Logo, de acordo com a exposição benjaminiana, na perspectiva do drama barroco opera-se uma inversão em que a figura do Príncipe entendido como tirano é caracterizado fundamentalmente pela indecisão. Em as Teses sobre o conceito de História, que pode ser compreendido como uma espécie de testamento de Walter Benjamin, de modo especial na tese VIII, o pensador de Berlim explicita de forma lapidar em que consiste esse instituto jurídico, do qual Giorgio Agamben compartilha e parte em suas análises. Vejamos: "A tradição dos oprimidos nos ensina que o 'estado de exceção' em que vivemos é na verdade a regra geral". ${ }^{30}$ Disso emerge a necessidade de um conceito de história que corresponda a essa verdade, em vista de originar um verdadeiro estado de exceção, na luta contra o fascismo. Nesse sentido, Reyes Mate, em sua importante releitura das teses benjaminianas, assevera:

28 BENJAMIN, Walter. Origem do drama trágico alemão. Tradução e edição de João Barrento. Belo Horizonte: Autêntica, 2012, p. 60.

29 BENJAMIN, Walter. Origem do drama trágico alemão. Tradução e edição de João Barrento. Belo Horizonte: Autêntica, 2012, p. 66. Uma leitura acerca dessa obra pode ser conferida em: BOLLE, Willi. A modernidade como "Trauerspiel”: Representação da história em W. Benjamín, “Origem do drama barroco alemão". Revista de História da USP, São Paulo, n. 119, 1988, p. 43-68.

30 BENJAMIN, Walter. Obras escolhidas. Magia e técnica, arte e política. Sérgio Paulo Rouanet. São Paulo: Ed. Brasiliense, 1996, p. 226. (Grifo nosso). Frente ao amplo crescimento do interesse pelo pensamento de Walter Benjamin, destacamos uma obra que em seu conjunto reflete os temas centrais dos quais o pensador berlinense se ocupou: MACHADO, Carlos Eduardo Jordão; MACHADO JR., Rubens; VEDDA, Miguel. (Orgs.). Walter Benjamin: experiência histórica e imagens dialéticas. 1. ed. São Paulo: UNESP, 2015. 
Agora como ontem, de fato, é verdade que, para os oprimidos, o estado de exceção é uma situação permanente. Nem a multiplicação do Estado social de Direito, nem o avanço da democracia liberal, nem o prestígio do discurso sobre os direitos humanos, nem o crescimento da riqueza mundial por obra e graça da globalização econômica, conseguiram mandar ao sótão dos pesadelos a contundente afirmação da tese VIII, a saber que todos esses progressos se dão sobre as costas de uma parte da humanidade. E se não há direito para alguns, ainda que fossem poucos, que não o são, a dúvida recai sobre a justiça de todo o direito. É certo que o direito é suspenso pela vontade dos poderosos, as guerras produzem mortos e a riqueza, miséria. ${ }^{31}$

Conforme enunciamos anteriormente, a análise acerca do estado de exceção está permeada pelo diálogo estabelecido entre Walter Benjamin e Carl Schmitt. Entretanto, de acordo com a posição agambeniana, podemos percebemos que frente ao intento de Carl Schmitt de (re) inscrever a violência no contexto jurídico, Walter Benjamin responde assegurando a ela (violência) - como violência pura ${ }^{32}$ - uma existência fora do direito - que rompe de um só golpe com a violência mítica. Essa discussão entre ambos pensadores alemães, embora visivelmente opostas, indica e põe em evidência uma zona de anomia que, por um lado, prevê a manutenção da relação com o direito e, por outro lado, deve ser inexoravelmente liberada dessa relação. ${ }^{33}$

\footnotetext{
31 MATE, Reyes. Meia-noite na história: comentários às teses de Walter Benjamin "sobre o conceito de história”. Tradução: Nélio Schneider, São Leopoldo, RS: Ed. Unisinos, 2011, p. 11.

32 A violência divina está para além do direito, acima do Estado, diferindo substancialmente da primeira (violência mítica) por ter uma semelhança com a violência do Estado. Nessa acepção, "Se o poder mítico é instituinte do direito, o poder divino é destruidor do direito; se aquele estabelece limites, este rebenta todos os limites". Por meio dessa forma de violência Divina é que se pode romper com toda forma de violência, o que indica para uma nova dimensão de plenitude de justiça, a possibilidade de irrupção do novo na história. BENJAMIN, Walter. Crítica da violência - crítica do poder. In: Documentos de cultura, documentos de barbárie. Tradução: Celeste H. M. Ribeiro de Souza et al. São Paulo: Cultrix, 1986, p. 173.

33 Acerca do debate entre Carl Schmitt e Walter Benjamin, observa Gilberto Bercovici: "O estado de exceção de Carl Schmitt defende a ordem contra a catástrofe. O estado de exceção de Walter Benjamin enxerga na ordem a catástrofe contínua da dominação". BERCOVICI,
} 
Em Crítica da violência, crítica do poder ${ }^{34}$, o pensador de Berlim delineia de início a questão crucial que orienta sua análise: "A tarefa de uma crítica da violência pode ser definida como a apresentação de suas relações com o direito e a justiça"35. A preocupação precípua parece sinalizar para o fato que toda a violência que emana socialmente tende a legitimar-se, e esta legitimação ocorre em estreita cumplicidade com o direito. Há, na acepção benjaminiana, uma coimplicação entre ambas - "violência" e "direito" - "Se a primeira função da violência passa a ser a instituição do direito, sua segunda função pode ser chamada de manutenção do direito" ${ }^{36}$. Conforme o exposto, a afirmação supramencionada revela que

a violência institui o direito como norma legal vigente e o direito legitima a violência como ato instituinte justo e força legítima que defende o próprio direito. [...] [Assim], não há direito fora da violência nem violência que não seja legitimada pelo direito. ${ }^{37}$

Diante dessa lógica, ambos (violência e direito) estão implicados intimamente de tal forma que se configuram como aliados inevitáveis, em que a violência aparece contida no direito e o direito coexiste e persiste pelo uso da força que gera e reproduz de modo continuado

Gilberto. Soberania e constituição: para uma crítica do constitucionalismo. São Paulo: Quartier Latin, 2008, p. 343.

34 Willi Bolle comenta acerca do título da obra. Vejamos: "Optei por esta tradução do original "Zur Kritik der Gewalt", uma vez que todo o ensaio é construído sobre a ambigüidade da palavra Gewalt, que pode significar ao mesmo tempo "violência" e "poder". A intenção de Benjamin é mostrar a origem do direito (e do poder judiciário) a partir do espírito da violência. Portanto, a semântica de Gewalt, neste texto, oscila constantemente entre esses dois polos [...]". BENJAMIN, Walter. Crítica da violência - crítica do poder. Tradução: Celeste H. M. Ribeiro de Souza et al. In: Documentos de cultura, documentos de barbárie. São Paulo: Cultrix, 1986, p. 160.

35 BENJAMIN, Walter. Crítica da violência - crítica do poder. In: Documentos de cultura, documentos de barbárie. Tradução: Celeste H. M. Ribeiro de Souza et al. São Paulo: Cultrix, 1986, p. 160.

${ }_{36}$ BENJAMIN, Walter. Crítica da violência - crítica do poder. In: Documentos de cultura, documentos de barbárie. Tradução: Celeste H. M. Ribeiro de Souza et al. São Paulo: Cultrix, 1986, p 165.

37 RUIZ, Castor Mari Martín Bartolomé. A justiça perante uma crítica ética da violência. In: RUIZ, Castor Mari Martín Bartolomé. Justiça e memória: para uma crítica ética da violência. São Leopoldo: Unisinos, 2009, p, 96. 
as barbáries na cotidianidade da vida. Daí que a instauração do estado de exceção, no entendimento de Walter Benjamin, submete o sujeito sem fissuras ao poder estabelecido ${ }^{38}$.

Assim, em face ao "paradoxo da soberania", a qual não se limita a enquadrar o que está dentro e o que está fora, a situação normal e o caos, acabam por traçar um limiar (a exceção) a partir do qual interno e externo entram em complexas relações topológicas, de tal forma que, em decorrência disso, tornam possível a validade do ordenamento jurídico. Logo, a exceção soberana, uma zona de indistinção entre natureza e direito, configura-se como a pressuposição da referência jurídica na esfera de sua suspensão. Vejamos:

A exceção que define a estrutura da soberania é, porém, ainda mais complexa. Aquilo que está fora vem aqui incluído não simplesmente através de uma interdição ou um internamento, mas suspendendo a validade do ordenamento, deixando, portanto, que ele se retire da exceção, a abandone. Não é a exceção que se subtrai à regra, mas a regra que, suspendendo-se, dá lugar à exceção e somente deste modo se constitui como regra, mantendo-se em relação com aquela. $O$ particular "vigor" da lei consiste nessa capacidade de manter-se em relação com uma exterioridade. Chamemos relação de exceção a esta forma extrema da relação que inclui alguma coisa unicamente através de sua exclusão. ${ }^{39}$

Diante dessa lógica exposta na passagem mencionada, torna-se explícita, embora complexa, a configuração do estado de exceção ${ }^{40}$, pois

\footnotetext{
${ }_{38}$ Conforme José Antonio Zamora, "Pero mientras que para Schmitt esta pretensión de poder resulta legítima y para ello basta su ejercício efectivo, el poder se legitima a sí mismo por su capacidad de establecer el nuevo "orden", Benjamin ve en este dato la prueba de la "corruptibilidad" de toda violencia jurídica. La estructura interna del derecho lo convierte en expresión del poder en cuanto violencia". ZAMORA, José Antonio. W. Benjamin: Crítica del capitalismo y la justicia mesiánica. In: RUIZ, Castor Mari Martín Bartolomé. (org.) Justiça e memória: para uma crítica ética da violência. São Leopoldo: Unisinos, 2009, p. 73.

39 AGAMBEN, Giorgio. . Homo sacer: o poder soberano e a vida nua I. Tradução: Henrique Burigo. 2. ed. Belo Horizonte: UFMG, 2010, p. 26. (grifo do autor)

40 Frente ao escopo da presente pesquisa, não nos deteremos em reconstruira a genealógica que o pensador italiano desenvolve ao longo da obra Estado de exceção, posto que se trata muito
} 
contém em si a própria suspensão, a inclusão através da suspensão, que por meio da decisão soberana instaura esse dispositivo jurídico-político. Ao instaurar a exceção por meio da decisão soberana suspende-se a norma, em que esta se aplica à exceção desaplicando-se, retirando-se desta, o que caracteriza o que se entende por estado de exceção. Isto é, configura-se uma "zona de anomia" em que a aplicação se separa da norma. Por conseguinte, "O estado de exceção separa, pois, a norma de sua aplicação para tornar possível a aplicação. Introduz no direito uma zona de anomia para tornar possível a normatização efetiva do real"41, que define as relações entre o direito e a vida, uma esfera que exerce poder de vida e sobre a vida do "vivente", em que um dos aspectos cruciais que emana disso é o caráter violento e arbitrário que se depreende do exercício de determinado poder soberano constituído, pelo exercício da soberania, sua peculiar "[...] natureza de paradigma constitutivo da ordem jurídica"42.

De acordo com Alfonso Galindo Hervás, dá-se quase que como a criação de um transcendental, ao se referir ao direito, o qual cria seu objeto, qual seja, a "vida corporal dos homens":

O poder soberano institui uma ordem tão somente enquanto que conserva a possibilidade de suspendê-la (isto é, de decidir a situação de exceção). E, em tal marco de excepcionalidade,

mais de indicar a lógica e estrutura sobre a qual o estado de exceção, dispositivo jurídico-político opera enquanto regra e constitutividade inscrita no coração da tradição político-jurídica do Ocidente. Entretanto, uma leitura detalhada, acerca da qual nos ocupamos em outro momento, a qual dialoga com seus usos e com contextos em que a exceção se mostra em seu caráter de permanência, pode ser vista em: 3.3 Estado de exceção, anomia jurídica e força-de-lei. In: PONTEL, Evandro. Estado de exceção: estudo em Giorgio Agamben. Passo Fundo: Ifibe, 2014, p. 123-145.

${ }^{41}$ AGAMBEN, Estado de exceção. Tradução: Iraci D. Poleti. 2. ed. São Paulo: Boitempo, 2004, p. 58.

42 AGAMBEN, Giorgio. Estado de exceção. Tradução: Iraci D. Poleti. 2. ed. São Paulo: Boitempo, 2004, p. 18. "Esse espaço vazio de direito parece ser, sob alguns aspectos, tão essencial à ordem jurídica que esta deve buscar, por todos os meios, assegurar uma relação com ele, como se, para se fundar, ela devesse manter-se necessariamente em relação com uma anomia. Por um lado, o vazio jurídico de que se trata no estado de exceção parece absolutamente impensável pelo direito; por outro lado, esse impensável se reveste, para a ordem jurídica, de uma relevância estratégica decisiva e que, de modo algum, se pode deixar escapar". AGAMBEN, Giorgio. Estado de exceção. Tradução: Iraci D. Poleti. 2. ed. São Paulo: Boitempo, 2004, p. 79. 
a operação essencial de tal poder é de isolamento, em cada sujeito, da vida nua ${ }^{43}$.

A vida, nessa acepção, não se encontra nem dentro e nem fora da lei, mas em uma "zona de indistinção", o que acaba por reduzi-la ao que o direito circunscreve e delimita, o qual cria sua referência, a pressupõe, (normaliza-a), abandona-a de acordo com a estrutura soberana da lei.

Isso, em última instância, torna o direito e a vida indistinguíveis, posto que a vida está implicada diretamente no direito por meio da "exceção" e o direito por integrá-la em si por meio da "inclusão exclusiva" (exceptio) da exceção, estrutura por excelência da soberania. Essa relação de indistinção fica clara nas palavras de Lauza Bazzicaluppo: "A forma da relação direito-vida é sempre soberana e é sempre biopolítica e funciona [...] através do paradoxo da exceção"44. Nesse sentido, a questão fulcral reside em que a exceção estabelece uma "zona de anomia" na qual se desenha uma "localização ou deslocalização", isto é, indica o lócus próprio que lhe cabe e onde se situa o estado de exceção que, paradoxalmente, mantém sua íntima relação com a ordem jurídica. ${ }^{45}$

Nessa perspectiva é de fundamental importância o legado de Jacques Derrida, motivo pelo qual o pensador italiano retoma a obra Força de lei: o fundamento místico da autoridade ${ }^{46}$, que contempla duas conferências

43 "El poder soberano instituye un orden sólo-en-tanto que conserva la posibilidad de suspenderlo (esto es, de decidir la situación de excepción). Y, en tal marco de excepcionalidad, la operación esencial de tal poder es el aislamiento, en cada sujeto, de la nuda vida". GALINDO HERVÁS, Alfonso. La soberania: de la teologia política al comunitarismo impolítico. Murcia: Res Publica, 2003, p. 107. (tradução nossa).

44 BAZZICALUPO, Laura. Biopolítica: um mapa conceitual. Tradução: Luisa Rabolini. São Leopoldo, RS: Unisinos, 2017, p. 98.

45 "Na verdade, o estado de exceção não é nem exterior nem interior ao ordenamento jurídico e o problema de sua definição diz respeito a um patamar, ou a uma zona de indiferença, em que dentro e fora não se excluem mas se indeterminam. A suspensão da norma não significa sua abolição e a zona de anomia por ela instaurada não é (ou pelo menos, não pretende ser) destituída de relação com a ordem jurídica". AGAMBEN, Giorgio. Estado de exceção. Tradução: Iraci D. Poleti. 2. ed. São Paulo: Boitempo, 2004, p. 39.

46 DERRIDA, Jacques. Força de lei: o fundamento místico da autoridade. Tradução: Leyla Perrone-Moisés. 2. ed. São Paulo: Editora WMF Martins Fontes, 2010. 
do pensador franco-argelino, quais sejam: "Do direito à justiça; Prenome de Benjamin". Na primeira parte o tema primordial indaga acerca da "desconstrução" como possibilidade de realização da justiça, tendo como eixo basilar os seguintes questionamentos: "será que a desconstrução assegura, permite, autoriza a possibilidade da justiça? Será que ela torna possível a justiça ou um discurso consequente sobre a justiça e sobre as condições de possibilidade da justiça?"47

Ao introduzir o tema, Jacques Derrida analisa expressões específicas do idioma inglês, relacionadas com aspectos internos de efetividade da lei, ou do direito, quais sejam: to enforce law - the enforceability of the law or of contract e distingue de Enforceability. Nesse sentido, Ricardo Timm de Souza explicita: "As expressões to enforce the law - como the enforceability of the law or of contract-, se diferenciam claramente de uma expressão mais 'neutra' como, por exemplo, 'aplicar a lei"48. Enforceability, "[...] nos lembra que não há direito que não implique nele mesmo, a priori, na estrutura analítica de seu conceito, possibilidade de ser "enforced", aplicado pela força ${ }^{49}$. Assim, essa força interna da expressão da língua inglesa parece, segundo ele conduzir à conclusão de que, por um lado, a justiça do direito é de algum modo a sua própria aplicação; e por outro, de que, por uma tal expressão, como que "não há direito que implique, em si mesmo, a priori, a estrutura analítica de seu conceito, a possibilidade de ser enforced, aplicado pela força" ${ }^{\prime \prime}$. Nesse sentido, certamente

47 DERRIDA, Jacques. Força de lei: o fundamento místico da autoridade. Tradução: Leyla Perrone-Moisés. 2. ed. São Paulo: Editora WMF Martins Fontes, 2010, p. 5. (grifo nosso). Para uma leitura acerca da relação entre Desconstrução e Justiça em Jacques Derrida, em uma perspectiva que situa seu contexto histórico-categorial e suas implicações disso na proposta derridiana, ver: SCAPINI, Marco Antonio de Abreu. Criminologia \& desconstrução: um ensaio. Rio de Janeiro: Lumen Juris, 2012, p. 3-83.

48 SOUZA, Ricardo Timm de. Derrida e a razão diferencial. In: Razões Plurais: itinerários da racionalidade ética no século XX. Porto Alegre: Edipucrs, 2004, p. 134.

49 DERRIDA, Jacques. Força de lei: o fundamento místico da autoridade. Tradução: Leyla Perrone-Moisés. 2. ed. São Paulo: Editora WMF Martins Fontes, 2010, p. 8. (grifo do autor).

50 SOUZA, Ricardo Timm de. Razões Plurais: itinerários da racionalidade ética no século $X X$. Porto Alegre: Edipucrs, 2004, p. 134. 
existem “[...] leis não aplicadas, mas não há lei sem aplicabilidade, e não há aplicabilidade ou "enforceability" de lei sem força, seja direta ou não, física ou simbólica, exterior ou interior, brutal ou sutilmente discursiva e hermenêutica, coercitiva ou reguladora, etc" ${ }^{\prime 51}$.

Na segunda parte da obra a análise endereça-se ao texto de Walter Benjamin, Crítica da violência, crítica do poder, em uma exposição que versa sobre "O nazismo e a 'solução final'. Os limites da respresentação", em que "[...] inscreve-se também numa perspectiva judaica que opõe a justa violência divina (judia) que destrói o direito, à violência mítica (da tradição grega), que instaura e conserva o direito"52. Giorgio Agamben ao reler a análise benjaminiana, observa que a proposição do pensador de Berlim consiste em

[...] garantir a possibilidade de uma violência (o termo alemão Gewalt significa também simplesmente "poder") absolutamente "fora" (ausserhalb) e "além" (jenseits) do direito e que, como tal, poderia quebrar a dialética entre violência que funda o direito e violência que o conserva (rechtsetzende und rechtserhaltende Gewalt). Benjamin chama essa outra figura da violência de "pura" (reine Gewalt) ou de "divina" e, na esfera humana, de "revolucionária". O que o direito não pode tolerar de modo algum, o que sente como uma ameaça contra a qual é impossível transigir, é a existência de uma violência fora do direito; não porque os fins de tal

51 DERRIDA, Jacques. Força de lei: o fundamento místico da autoridade. Tradução: Leyla Perrone-Moisés. 2. ed. São Paulo: Editora WMF Martins Fontes, 2010, p. 8-9. Conferir: SOUZA, Ricardo Timm de. Razões Plurais: itinerários da racionalidade ética no século XX, p. 130-166. Frente ao escopo da presente investigação não nos deteremos em abordar exaustivamente a obra do pensador franco-argelino, como por exemplo, as aporias presentes na discussão sobre a justiça e a desconstrução. Uma leitura detalhada que pontua tais questões e dialoga com o tema da biopolítica, pode ser conferida em: TISSERA, Guillermo Damián Pereyra. Deconstrucción y biopolítica: el problema de la ley y la violencia en Derrida y Agamben. Perspectivas Teóricas. Revista Mexicana de Ciencias Políticas y Sociales, México, v. 56 n. 212, may/ago, 2011, p. 31-54. 52 DERRIDA, Jacques. Força de lei: o fundamento místico da autoridade. Tradução: Leyla Perrone-Moisés. 2. ed. São Paulo: Editora WMF Martins Fontes, 2010, p. 62. (grifo do autor). 
violência sejam incompatíveis com o direito, mas "pelo simples fato de sua existência fora do direito." ${ }^{53}$

A exposição acima delineada pode ser explicitada da seguinte forma: a partir da distinção entre duas violências, a violência fundadora e a violência conservadora (entendida como violência mítica), mas tendo em consideração que aquela é por vezes representada nessa em uma "contaminação diferencial"54. Ou seja, nesse viés não há uma espécie de rompimento, mas uma refundação para conservação em sentido de uma dialética circular. Nesse âmbito, Benjamin parece apresentar uma solução como possibilidade à crise do conceito de direito55, enquanto insígnia peculiar do modelo europeu de democracia burguesa e liberal, através da postulação de uma violência destruidora do direito ${ }^{56}$. Jacques Derrida, nesse sentido, afirma:

A essa violência do mýtos grego, Benjamin opõe, traço por traço, a violência de Deus. De todos os pontos de vista, diz ele, ela é o contrário daquela. Em vez de fundar o direito, ela o destrói. Em vez de colocar limites e fronteiras, ela os aniquila. Em vez de anular, ao mesmo tempo, o erro e a expiação, ela faz expiar. Em vez de ameaçar, ela fulmina. ${ }^{57}$

\footnotetext{
53 AGAMBEN, Giorgio. Estado de exceção. Tradução: Iraci D. Poleti. 2. ed. São Paulo: Boitempo, 2004, p. 84-85. (grifo do autor).

54 A formulação derridina que segue é lapidar: "A conservação, por sua vez, é ainda re-fundadora para poder conservar o que se pretende fundar. Não há, portanto oposição rigorosa entre a instauração e a conservação, somente aquilo que chamarei (e que Benjamin não nomeia) de contaminação diferencial entre as duas [...]" DERRIDA, Jacques. Força de lei: o fundamento místico da autoridade. Tradução: Leyla Perrone-Moisés. 2. ed. São Paulo: Editora WMF Martins Fontes, 2010, p. 90. (Grifo do autor).

55 Cf. DERRIDA, Jacques. Força de lei: o fundamento místico da autoridade. Tradução: Leyla Perrone-Moisés. 2. ed. São Paulo: Editora WMF Martins Fontes, 2010, p. 90-91.

${ }_{56}$ DERRIDA, Jacques. Força de lei: o fundamento místico da autoridade. Tradução: Leyla Perrone-Moisés. 2. ed. São Paulo: Editora WMF Martins Fontes, 2010, p. 74.

57 DERRIDA, Jacques. Força de lei: o fundamento místico da autoridade. Tradução: Leyla Perrone-Moisés. 2. ed. São Paulo: Editora WMF Martins Fontes, 2010, p. 122.
} 
Um dos fatores relevantes realçados por Jacques Derrida reside no fato de que Benjamin parece ter tido por indagação medular colocar em questão o interesse que o direito tem de instaurar e conservar a si mesmo e, por conseguinte, o monopólio da violência, Gewalt, isto é, violência entendida, também na forma de autoridade por meio da polícia, (exemplo moderno). Aliás, cumpre observar, essa é caracterizada e destacada como uma figura sem rosto mas que age sob mera força de lei - em detrimento de determinados valores justos. Dito de outro modo, a polícia é entendida como aquela capaz de suspender a separação da violência que funda e conserva o direito, pois seu comportamento se assemelha ao de um legislador nos tempos modernos, pois sua atuação excede a o simples fato de aplicar “[...] a lei pela força (enforce) e, portanto em conservá-la [...] Ela é a força de lei, ela tem força de lei [...] inventa o direito, ela se faz legislativa, ela se atribui o direito cada vez que este é suficientemente indeterminado [...]"58. Portanto, a polícia moderna configura em uma espécie de "[...] local onde ex-surge um ponto cego da soberania política: a polícia" ${ }^{59}$, em um panorama político-técnico no qual acaba por produzir a lei que somente deveria aplicar ${ }^{60}$.

A análise desenvolvida por Jacques Derrida sinaliza para o sentido de que Benjamin não busca pensar uma finalidade, uma justiça dos fins que já não esteja ligada à possibilidade do direito, como algo concebido como universalizável, a qual esteja inscrita no conceito de justiça. No entanto, se destaca o aspecto que o pensador alemão põe em Deus, "com aquele que decide acerca da legitimidade dos meios da justiça

58 DERRIDA, Jacques. Força de lei: o fundamento místico da autoridade. Tradução: Leyla Perrone-Moisés. 2. ed. São Paulo: Editora WMF Martins Fontes, 2010, p. 99 (grifo do autor).

59 AMARAL, Augusto Jobim do. Ostensividade da soberania policial. In: (orgs.). GLOECKNER, Ricardo Jacobsen; FRANÇA, Leandro Ayres; RIGON, Bruno Silveira. Biopolíticas: estudos sobre política, governamentalidade e violência. Curitiba: iEA Academia, 2015, p. 301 (grifo do autor).

6o Sobre a soberana violência policial, ver: AMARAL, Augusto Jobim do. Ostensividade da soberania policial. In: (orgs.). GLOECKNER, Ricardo Jacobsen; FRANÇA, Leandro Ayres; RIGON, Bruno Silveira. Biopolíticas: estudos sobre política, governamentalidade e violência. Curitiba: iEA Academia, 2015, p. 301-318. 
dos fins acima da razão e mesmo acima da violência do destino"61. Esse posicionamento evidencia a compreensão de uma justiça sem direito, uma justiça para além do direito.

Ao longo da exposição, na compreensão agambeniana, o exercício filosófico elaborado pelo pensador franco-argelino é sumamente relevante e primordial, tendo em vista que a compreensão de "força de lei" até então ainda não havia sido pensada no interior da tradição jurídica. Ou seja, a fórmula aparentemente enigmática que intitula a referida obra. Embora força de lei, sendo um conceito crucial, esteja vinculada ao direito romano e medieval, que tem o sentido geral de "eficácia", como capacidade de obrigar, desde um ponto de vista técnico, ancorado na doutrina moderna, é distinto de um viés da eficácia da lei, pois esta última expressaria somente a produção de efeitos jurídicos, ao passo que, em sentido oposto, força de lei revela a posição da lei em relação a outros atos do ordenamento jurídico, com força superior, a exemplo da Constituição. Entretanto, é importante destacar e observar que "[...] o sintagma força de lei se refira, tanto na doutrina moderna quanto na antiga, não à lei, mas àqueles decretos - que têm justamente, como se diz, força de lei - que o poder executivo pode, em alguns casos - particularmente, no estado de exceção - promulgar."62

Nesse ínterim, define-se um estado da lei em que, de um lado, a lei está em vigor, mas não tem aplicabilidade (não tem força) e, de outro lado, os atos que não têm valor de lei adquirem sua força, em uma explícita separação entre lei e força de lei. Trata-se de um espaço anômico no qual, conforme sustenta Agamben, o que está em jogo é uma força de lei sem lei, logo, força-de-lei ${ }^{63}$. É nesse espaço anômico produzido no

${ }^{61}$ DERRIDA, Jacques. Força de lei: o fundamento místico da autoridade. Tradução: Leyla Perrone-Moisés. 2. ed. São Paulo: Editora WMF Martins Fontes, 2010, p. 119, (grifo do autor.

62 AGAMBEN, Giorgio. Estado de exceção. Tradução: Iraci D. Poleti. 2. ed. São Paulo: Boitempo, 2004, p. 60.

${ }_{63}$ Segundo Moyses Pinto Neto, força-de-lei, "Tachado [indica que] a lei tachada porque não se trata propriamente de uma lei, mas de algo que se substitui a ela sem sua revogação (como a 
interior da ordem jurídica, sem que se tenha comprometido a vigência formal das normas, que se pode, por exemplo, entender, situar tanto o "nazismo" quanto o "fascismo" em sua constituição, experiências nas quais se mantiveram acompanhadas por uma estrutura delimitada como um paradigma de uma "estrutura dual" isto é, "[...] a constituição legal de uma segunda estrutura, amiúde não formalizada juridicamente, que podia existir ao lado da outra graças ao estado de exceção"64.

O panorama em curso da política atual, na contemporaneidade, requer que seja posto em questão o nexo entre o "direito" e a "violência", a violência no interior do vazio de direito, do estado de exceção - que se configura como estrutura política fundamental presente nos tempos atuais; compreender a ficção constitutiva que liga norma e anomia, lei e estado de exceção e garante também a relação entre o "direito" e a "vida". Nesse viés, o estado de exceção é um "vazio de direito" porque é um "[...] espaço anômico onde o que está em jogo é uma força-de-lei sem lei ${ }^{6 "}$ ", portanto, força-de-lei, que se configura como um espaço de indistinção - conjuga o vazio de direito no espaço anômico, como um vazio e uma interrupção do direito, uma zona de indiferença entre o caos e o estado de normalidade capturado pela norma, de modo que não

\footnotetext{
"palavra do Führer" durante o nazismo, que Eichmann não cansava de afirmar ter "força de lei". NETO, Moysés da Fontoura Pinto. $O$ rosto do inimigo: um convite à desconstrução do direito penal do inimigo. Rio de Janeiro: Lumen Juris, 2012, p. 22.

${ }_{64}$ AGAMBEN, Giorgio. Estado de exceção. Tradução: Iraci D. Poleti. 2. ed. São Paulo: Boitempo, 2004, p. 76. Nesse sentido, Hannah Arendt, na obra Eichmann em Jerusalém: um relato sobre a banalidade do mal, explicita o modo como se entendia, nesse período, a ordem e a lei, como a ordem acaba por ser vista como lei ou mesmo ter status de força de lei. Conforme a pensadora relata: "Eichmann, muito menos inteligente e sem nenhuma formação, percebeu pelo menos vagamente que não era uma ordem, mas a própria lei que os havia transformado todos em criminosos. Uma ordem diferia da palavra do Führer porque a validade desta última não era limitada no tempo e no espaço - a característica mais notável da primeira. Essa é também a verdadeira razão pela qual a ordem do Führer para a Solução Final foi seguida por uma tempestade de regulamentos e diretivas, todos elaborados por advogados peritos e conselheiros legais, não por meros administradores; essa ordem, ao contrário de ordens comuns foi tratada como lei". ARENDT, Hannah. Eichmann em Jerusalém: um relato sobre a banalidade do mal. Tradução: Josué Rubens Siqueira. São Paulo: Cia das Letras, 1999, p. 167.

${ }_{65}$ AGAMBEN, Giorgio. Estado de exceção. Tradução: Iraci D. Poleti. 2. ed. São Paulo: Boitempo, 2004, p. 61.
} 
é a exceção que se subtrai à norma, mas esta que, suspendendo-se, dá lugar à exceção. Por conseguinte, é a suspensão da regra que dá lugar à exceção e somente desse modo se constitui como regra, mantendo-se em relação com aquela:

O estado de exceção é, nesse sentido, a abertura de um espaço em que aplicação e norma mostram sua separação e em que uma pura força-de-lei (isto é, aplica desaplicando) uma norma cuja aplicação foi suspensa. Desse modo, a união impossível entre norma e realidade, e a consequente constituição do âmbito da norma, é operada sob a forma da exceção, isto é, pelo pressuposto de sua relação. Isso significa que, para aplicar uma norma, é necessário, em última análise, suspender sua aplicação, produzir uma exceção. Em todos os casos, o estado de exceção marca um patamar onde lógica e práxis se indeterminam e onde uma pura violência sem logos pretende realizar um enunciado sem nenhuma referencia real. ${ }^{66}$

A exceção, espaço anômico, um aplicar-se desaplicando-se, expressa a íntima relação entre norma jurídica que está em vigor, vigente, mas não se aplica, como pura potência e, de outro, atos que não possuem validade de lei, mas tem sua força, através do sintagma força-de-lei que "[...] no caso extremo, pois "força-de-lei" flutua como um elemento indeterminado, que pode ser reivindicado pela autoridade estatal [...]"67. A exceção se configura como uma espécie de exclusão, um caso singular excluído da norma geral, em que aquilo que é excluído não se mantém em relação com a norma em forma de suspensão: " $A$ norma se aplica à exceção desaplicando-se, retirando-se desta. O estado de

\footnotetext{
${ }_{66}$ AGAMBEN, Giorgio. Estado de exceção. Tradução: Iraci D. Poleti. 2. ed. São Paulo: Boitempo, 2004, p. 63. (Grifo do autor).

${ }_{67}$ AGAMBEN, Giorgio. Estado de exceção. Tradução: Iraci D. Poleti. 2. ed. São Paulo: Boitempo, 2004, p. 61.
} 
exceção não é, portanto, o caos que precede a ordem, mas a situação que resulta da sua suspensão." 68

Enfim, vimos que a máquina governamental se estrutura sob a exceção, que determina a vida tanto em sentido jurídico, político, econômico, cultural, como fator fundante na civilização ocidental desde os tempos primitivos. Nessa acepção, como dispositivo que captura a vida, em que o humano é mero sobrevivente na marcha da história, entendida como o progresso, (sociedade do espetáculo) que produz e delineia as subjetividades, como consumidores ávidos de satisfação de seus desejos e necessidades, presenciamos a consolidação desse paradigma biopolítico de governo que suprime direitos, garantias e liberdades e legitima as mais variadas práticas totalitárias, em um panorama em que "[...] o estado de exceção, hoje, atingiu o máximo desdobramento planetário", 69 no qual a guerra civil, stasis ${ }^{70}$ é o paradigma dominante da ação política dos Estados ao redor do globo.

$\mathrm{Na}$ obra Stasis o pensador italiano elabora um estudo sobre o conceito que intitula a obra, recuperando-o desde sua origem no horizonte da polis grega, no qual a "guerra civil" funcionava como um limiar de politização e de despolitização, por meio da qual a casa se excedia em

68 AGAMBEN. Giorgio. Homo sacer: o poder soberano e a vida nua I. Tradução: Henrique Burigo. 2. ed. Belo Horizonte: UFMG, 2010, p. 24. (Grifo do autor) Castor Mari Martín Bartolomé Ruiz observa: "O paradoxal da exceção é que é concomitante ao Estado de Direito. O que é ainda mais paradoxal é que o Estado de Direito vem utilizando a exceção muito frequentemente como dispositivo de controle de pessoas e populações". RUIZ, Castor Mari Martín Bartolomé. A relação paradoxal da filosofia e os direitos humanos. Prefácio. In: CARBONARI, Paulo César. (org.) Sentido filosófico dos direitos humanos: leituras do pensamento contemporâneo 3. Passo Fundo: Ifibe, 2013, p. 35.

69 AGAMBEN, Giorgio. Estado de exceção. Tradução: Iraci D. Poleti. 2. ed. São Paulo: Boitempo, p. 131. Ana Suelen Tossige Gomes e Andityas Soares de Moura Costa Matos, analisam a prática excepcional no Brasil republicano (1889-2014), o estado de exceção, o estado de sítio, utilizado como técnica de governamentalidade antes mesmo da I Guerra Mundial. Esta prática excepcional se manifesta nos diversos instrumentos e se estende por todo o período republicano de modo contínuo, mesclando-se com a "normalidade" garantida pelo direito comum. Ver: GOMES, Ana Suelen Tossige; MATOS, Andityas Soares de Moura Costa. O estado de exceção no Brasil republicano. Revista Direito e Práxis. Rio de Janeiro, v. 8, n. 3, 2017, p. 1760-1787.

70 Cf. AGAMBEN, Giorgio. Stasis: la guerra come paradigma politico. Totino: Bollati Boringhieri, 2015 . 
cidade e a cidade se despolitiza na família. A hipótese proposta indica que a Stasis não tem lugar nem na polis, nem na cidade, e nem na família: essa se constitui em uma "zona de indiferença" entre o espaço impolítico da família e aquele da cidade. Assim,

A stasis não provêm do oikos, não é uma guerra em família, mas é parte de um dispositivo que funciona de modo similar ao estado de exeção. Como no estado de exceção, a zóe, na vida natural, é incluída na ordem jurídico-política através da sua exclusão, em um modo análogo através do qual a stasis do oikos é politizada e incluída na polis (tradução nossa) ${ }^{71}$.

Nesse sentido, como podemos perceber, o que está em jogo é um "limiar de indiferença" em que político e impolítico, o fora e o dentro coincidem. Destarte, então, a política deve ser concebida como um campo de forças e os extremos, quais sejam: o oikos e a polis: entre esses a "guerra civil" assinala um limiar por meio do qual transita e o impolítico se politiza e o político se economiciza. Esse paradigma da "guerra civil", paradigma político presente no Ocidente se expressa de um modo ímpar no terrorismo, haja vista que a vida se torna aquilo que está posto em jogo na política, sobre aquilo que se demarca a cada momento determinadas zonas do espaço planetário ${ }^{72}$.

Nessa perspectiva, poderíamos situar paradigmaticamente os eventos ocorridos no decorrer do século XX, os campos de concentração [Auschwitz] da Segunda Guerra Mundial, Hiroshima e Nagasaki e, desde então, mas com maior urgência a situação dos migrantes - desde a crise e a falência do Estado-nação em sua tarefa de garantir direitos, a vida dos migrantes na atualidade - em um campo de força político econômico demarcado pela produção de discursividades estigmatizantes e xenofóbi-

\footnotetext{
71 Do original: La stasis non proviene dall'oikos, non è una guerra in famiglia, ma è parte di un dispositivo che funziona in modo simile allo stato di eccezione. Come, nello stato di eccezione, la zoé, la vita naturale, è inclusa nell ordine giuridico-politico attraverso la sua esclusione, in modo analogo attraverso la stasis l'oikos è politizzato e incluso na polis". AGAMBEN, Giorgio. Stasis: la guerra come paradigma politico. Totino: Bollati Boringhieri, 2015, p. 30.

72 Ver: NEUTLING; Inácio; RUIZ, Castor Mari Martín Bartolomé. (orgs.). O (des)governo da vida humana. São Leopoldo: Casa Leiria, 2011.
} 
cas que os veem como ameaça. Esses acontecimentos dão o que pensar e colocam em xeque a própria estrutura da racionalidade totalizante da racionalidade ocidental73, que ao incluir a vida a captura e a dispõe de acordo com as estratégias de poder estabelecidas pelos Estados que se pretendem Estados democráticos de direito. Porém, diante dessa maciça estrutura de barbáries presenciadas pelo anjo da história benjaminiano que se acumulam até os céus, "o que ainda resta fazer?"

Um desafio que perpassa a investigação de Giorgio Agamben está posto antes mesmo da inauguração do projeto homo sacer que data de 1995 com a obra Homo sacer: o poder soberano e a vida nua I, que reside no desafio de colocar em xeque os conceitos que ainda regem a política no Ocidente, presente já em Meios sem fim, cuja tarefa indica a necessidade de conceber a vida como aquilo que se põe em jogo, no seu viver mesmo, em sua vivibilidade, no seu endereçamento à felicidade. Isto é, em conceber o humano e a política enquanto desconexão, desativação dos dispositivos e das articulações legadas pela tradição metafísica ocidental (logos/natureza, corpo/alma, anomia/lei, essência/existência), que ainda reinam, mapeiam, incluem e tornam a vida objeto cindido e capturado nas esferas de poder, qual seja: "Devemos tentar pensar o humano e o político como aquilo que resulta da desconexão desses elementos e investigar não o mistério metafísico da conjunção, mas aquele prático e político de sua disjunção."74

Em suma, é nesse complexo panorama que podemos situar, conforme buscamos demonstrar por meio da lúcida e crítica leitura do pensador italiano, enquanto um prognóstico preciso das condições nas quais a vida está posta em xeque na cena política. É nesse ínterim que se torna ímpar sua proposta filosófica, justamente por ser capaz de colocar em questão,

\footnotetext{
73 Cf. SOUZA, Ricardo Timm de. (Dis)pensar o ídolo. Responsabilidade radical no pensamento contemporâneo. Rivista Quadranti, Salerno, v. 2, n. 2014, p. 69-87.

74 AGAMBEN, Giorgio. O uso dos corpos. Tradução: Selvino José Assmann. São Paulo: Boitempo, 2017, p. 304.
} 
a nu aquilo que subjaz à estruturação do tecido social ao qual estamos implicados em pleno século XXI. Talvez, a partir de seu legado, e para além dele, a tarefa por excelência do pensamento enquanto potência e da "filosofia que vem", consista, precisamente, em repensar as categorias que ainda regem o estatuto da política ocidental, pensar a vida ainda além do poder, enquanto potencialidade e possibilidade de reinventar-se em formas-de-vida, de pensar novos usos de si e das coisas, uma vida que possa estar intimamente ligada ao seu modo de ser: consiste, portanto, em conceber e estabelecer um "[...] um bios, um modo de vida, que se define apenas por especial e inseparável união com a zoé e não tem outro conteúdo que sua forma, (e, reciprocamente, o fato de se dar uma zoé que nada mais é do que sua forma, seu bios"75, de tal modo que se possa constituir e construir um ethos no qual a vida possa ser um fim em si mesmo.

\section{Referências}

AGAMBEN, Giorgio. Estado de exceção. Tradução Iraci D. Poleti. 2. ed. São Paulo: Boitempo, 2004.

AGAMBEN, Giorgio. O que é o contemporâneo? e outros ensaios. Tradução Vinícius Nicastro Honesko. Chapecó: Argos, 2009.

AGAMBEN, Giorgio. Homo sacer: o poder soberano e a vida nua I. Tradução Henrique Burigo. 2. ed. Belo Horizonte: UFMG, 2010.

AGAMBEN, Giorgio. Uma cidadania reduzida a dados biométricos: como a obsessão securitária faz mudar a democracia. In: GLOECKNER, Ricardo Jacobsen; FRANÇA, Leandro Ayres; RIGON, Bruno Silveira. (org.). Biopolíticas: estudos sobre política, governamentalidade e violência. Trad. Daniel Arruda Nascimento, Curitiba: iEA Academia, 2015.

AGAMBEN, Giorgio. Stasis: la guerra come paradigma politico. Totino: Bollati Boringhieri, 2015.

75 AGAMBEN, Giorgio. O uso dos corpos. Tradução: Selvino José Assmann. São Paulo: Boitempo, 2017, p. 246. (Grifo do autor). 
AGAMBEN, Giorgio. O uso dos corpos. Tradução Selvino José Assmann. São Paulo: Boitempo, 2017.

AMARAL, Augusto Jobim do. Ostensividade da soberania policial. In: GLOECKNER, Ricardo Jacobsen; FRANÇA, Leandro Ayres; RIGON, Bruno Silveira (org.). Biopolíticas: estudos sobre política, governamentalidade e violência. Curitiba: iEA Academia, 2015. p. 301-318.

BARBER, Benjamin R. O império do medo: guerra, terrorismo e democracia. Trad. Renato Bittencourt. Rio de Janeiro: Record, 2005.

BAZZICALUPO, Laura. Biopolítica: um mapa conceitual. Tradução Luisa Rabolini. São Leopoldo, RS: Unisinos, 2017.

BENJAMIN, Walter. Crítica da violência - crítica do poder. In: DOCUMENTOS de cultura, documentos de barbárie. São Paulo: Cultrix, 1986. p. 160-175.

BENJAMIN, Walter. Obras escolhidas. Magia e técnica, arte e política. São Paulo: Ed. Brasiliense, 1996.

BENJAMIN, Walter. Origem do drama trágico alemão. Tradução e edição de João Barrento. Belo Horizonte: Autêntica, 2012.

BERCOVICI, Gilberto. Constituição e estado de exceção permanente: atualidade de Weimar. Rio de Janeiro: Azougue Editorial, 2004.

BERCOVICI, Gilberto. Soberania e constituição: para uma crítica do constitucionalismo. São Paulo: Quartier Latin, 2008.

BUTLER, Judith. Vida precaria: el poder del duelo y la violencia. Tradução Fermín Rodríguez. Buenos Aires: Paidós, 2006.

BUTLER, Judith. Quadros de guerra: quando a vida é passível de luto? 3. ed. Tradução Sérgio Tadeu de Niemayer Lamarão e Arnaldo Marques da Cunha. Rio de Janeiro: Civilização Brasileira, 2017.

CASTRO, Edgardo.Introdução a Giorgio Agamben: uma arqueologia da potência. Trad. Beatriz de Almeida Magalhães. Belo Horizonte: Autêntica, 2012.

DERRIDA, Jacques. Força de lei: o fundamento místico da autoridade. Tradução Leyla Perrone-Moisés. 2. ed. São Paulo: Editora WMF Martins Fontes, 2010.

DOUZINAS, Costas. O fim dos direitos humanos. Trad. Luzia Araújo. São Leopoldo: Unisinos, 2009.

DURANTEYE, Leland de la. Giorgio Agamben: a critical introduction. Stanford: Stanford University Press, 2009. 
ARENDT, Hannah. Eichmann em Jerusalém: um relato sobre a banalidade do mal. Tradução Josué Rubens Siqueira. São Paulo: Cia das Letras, 1999. https:// doi.org/10.5433/1980-511x.2019v14n1p204

GALINDO HERVÁS, Alfonso. La soberania: de la teologia política al comunitarismo impolítico. Murcia: Res Publica, 2003.

GOMES, Ana Suelen Tossige; MATOS, Andityas Soares de Moura Costa. O estado de exceção no Brasil republicano. Revista Direito e Práxis, Rio de Janeiro, v. 08, n. 3, p. 1760-1787, 2017. https://doi.org/10.1590/2179-8966/2017/21373 KAFKA, Franz. Ante la ley. In: KAFKA, Franz. Obras completas. Tradução Joan Bosch Estrada et. al. [S. l.]: [s. n.], [19--].Tomo IV.

MACHADO, Carlos Eduardo Jordão; MACHADO JR., Rubens; VEDDA, Miguel. (org.). Walter Benjamin: experiência histórica e imagens dialéticas. 1. ed. São Paulo: UNESP, 2015. https://doi.org/10.1590/1980-436920170000000015

MATE, Reyes. Meia-noite na história: comentários às teses de Walter Benjamin "sobre o conceito de história". Tradução Nélio Schneider, São Leopoldo, RS: Ed. Unisinos, 2011.

NASCIMENTO, Daniel Arruda. Do fim da experiência ao fim do jurídico: percurso de Giorgio Agamben. São Paulo: LiberArs, 2012.

NETO, Moysés da Fontoura Pinto. $O$ rosto do inimigo: um convite à desconstrução do direito penal do inimigo. Rio de Janeiro: Lumen Juris, 2012. https:// doi.org/10.17771/pucrio.acad.37975

NEUTLING; Inácio; RUIZ, Castor Mari Martín Bartolomé. (org.). O (des)governo da vida humana. São Leopoldo: Casa Leiria, 2011.

PONTEL, Evandro. Estado de exceção: estudo em Giorgio Agamben. Passo Fundo: Ifibe, 2014.

RUIZ, Castor Mari Martín Bartolomé. Introdução. In: RUIZ, Castor Mari Martín Bartolomé. (org.) Justiça e memória: direito à justiça, memória e reparação, a condição humana nos estados de exceção, 2012. https://doi. org/10.21527/2317-5389.2017.9.331-348

RUIZ, Castor Mari Martín Bartolomé. A relação paradoxal da filosofia e os direitos humanos. Prefácio. In: CARBONARI, Paulo César. (org.). Sentido filosófico dos direitos humanos: leituras do pensamento contemporâneo 3. Passo Fundo: Ifibe, 2013. 
SELIGMANN-SILVA, Márcio. Walter Benjamin: o Estado de Exceção entre o político e o estético. Cadernos Benjaminianos, Belo Horizonte, n. 1, p. 1-23, 2009. https://doi.org/10.17851/2179-8478.0.1.1-25

SCAPINI, Marco Antonio de Abreu. Criminologia \& desconstrução: um ensaio. Rio de Janeiro: Lumen Juris, 2012.

SCHMITT, Carl. Teologia política. Tradução Elisete Antoniuk. Belo Horizonte: Del Rey, 2006.

SOUZA, Ricardo Timm de. Razões Plurais: itinerários da racionalidade ética no século XX. Porto Alegre: EDIPUCRS, 2004. p. 130-166.

TISSERA, Guillermo Damián Pereyra. Deconstrucción y biopolítica: el problema de la ley y la violencia en Derrida y Agamben. Perspectivas Teóricas. Revista Mexicana de Ciencias Políticas y Sociales, México, v. 56, n. 212, p. 31-54, may/ ago. 2011. https://doi.org/10.22201/fcpys.2448492xe.2011.212.30397

ZAMORA, José Antonio. W. Benjamin: crítica del capitalismo y la justicia mesiánica. In: RUIZ, Castor Mari Martín Bartolomé. (org.). Justiça e memória: para uma crítica ética da violência. São Leopoldo: Unisinos, 2009.

\section{Endereço postal}

Pontifícia Universidade Católica do Rio Grande do Sul - (PUCRS)

Programa de Pós-Graduação em Filosofia

Av. Ipiranga, 6681 - Prédio $8-4^{\circ}$ andar - Sala 403.

CEP 90.619-900 - Partenon, Porto Alegre, RS - Brasil. 